\title{
Corneal Thinning after Contact Lens-related Infective Keratitis
}

\author{
${ }^{1}$ Raquel Almeida, ${ }^{2}$ Filipa Rodrigues, ${ }^{3}$ Matheus Santos, ${ }^{4}$ Renata Siqueira, ${ }^{5}$ Patrícia Contarini
}

${ }^{6}$ José Salgado-Borges, ${ }^{7}$ Renato Ambrosio Jr

\section{ABSTRACT}

Purpose: To describe two cases of contact lens-related infectious keratitis with secondary corneal thinning.

Material and methods: Case reports and review of the literature.

Results: The first case is of a 13-year-old girl, contact lens user, admitted for acute corneal infection in her right eye (OD). Seven years after treatment, she presented with corneal thinning and flattening with uncorrected distance visual acuity of 20/30 OD; thinnest value was $363 \mu \mathrm{m}$ in OD and $513 \mu \mathrm{m}$ in the left eye (OS). The second case is a 22-year-old male, cosmetic contact lens user, first presented with severe keratitis in OD. One year after treatment, the eye was quiet with moderate corneal opacity; corneal thickness was $228 \mu \mathrm{m}$ OD and $561 \mu \mathrm{m}$ OS. Ectasia was identified due to the protrusion and steepening with an irregular curvature pattern. Rigid gas permeable (RGP) contact lens fitting enabled visual acuity of 20/25 OD.

Conclusion: Corneal melt with secondary stromal loss and thinning may lead or not to secondary ectasia. Visual rehabilitation is possible with RGP contact lenses despite corneal opacity. The risk of infectious keratitis among contact lenses users should be considered.

Keywords: Corneal ulcers, Ectasia, Contact lenses.

How to cite this article: Almeida R, Rodrigues F, Santos M, Siqueira R, Contarini P, Salgado-Borges J, Ambrosio R Jr.

\footnotetext{
${ }^{1,2}$ Resident, ${ }^{3}$ Medical Student, ${ }^{4,5}$ Research Associate

${ }^{6,7}$ Clinical Director

1,2Department of Ophthalmology, Centro Hospitalar de Entre o Douro e Vouga, Portugal

${ }^{3}$ Department of Faculdade de Medicina, Universidade Federal de Sergipe, Brazil

${ }^{4}$ Department of Ophthalmology, Instituto de Olhos Renato Ambrósio, Brazil

${ }^{5}$ Department of Research Associate, Corneal Tomography and Biomechanics Study Group, Brazil

${ }^{6}$ Department of Ophthalmology, Hospital Escola, Universidade Fernando Pessoa, Portugal

${ }^{7}$ Department of Cornea and Refractive Surgery, Instituto de Olhos Renato Ambrósio, Brazil
}

Corresponding Author: Raquel Almeida, Resident Department of Ophthalmology, Centro Hospitalar de Entre o Douro e Vouga, Portugal, Phone: 00351918200664, e-mail: raquelribeiroalmeida@gmail.com
Corneal Thinning after Contact Lens-related Infective Keratitis. Int J Kerat Ect Cor Dis 2014;3(2):95-98.

\section{Source of support: Nil}

Conflict of interest: None declared

\section{INTRODUCTION}

Corneal ectasia is characterized by thinning and protrusion. Ectatic diseases comprise a range of disorders involving either primary disease conditions such as keratoconus, keratoglobus and pellucid marginal degeneration or secondary ectatic conditions, such as keratectasia after LASIK. ${ }^{1,2}$ Ectasia may also develop after trauma or corneal infection. The condition occurs when there is biomechanical failure so that the normally round dome-shaped cornea progressively assumes a cone-like bulge or forward protrusion, a response of a thin and weak cornea to the normal pressure of the eye. ${ }^{3,4}$ Thinning occurs primarily in the stromal layers. The bulging can lead to an irregular shape or astigmatism of the cornea and usually results in loss of visual acuity which can make even simple daily tasks, such as driving, watching television or reading, difficult to perform. ${ }^{5}$

Corneal remodeling may occur through epithelial thinning and modulation, leading to partial homogenization of the anterior corneal surface for maintaining visual acuity. ${ }^{6}$ Remodeling may occur following riboflavin ultraviolet (UV)-A induced corneal collagen cross-linking (UV-A), but also following an event that results in focal corneal scarring, such as corneal infection. In a highly irregular cornea, the benefit of the flattening effect of a scar may outweigh the increase in aberrations and light scatter. ${ }^{7}$

\section{CASE REPORT}

The first case is of a 13-year-old girl who was admitted in the Ophthalmology Department of Centro Hospitalar de Entre o Douro e Vouga, Feira, Portugal, for acute corneal infection in her right eye (OD). She had started wearing contact lens 4 months before and her distance corrected visual acuity (DCVA) was 20/20 both eyes (OU), with a minus sphere of 2.5D. She had no history of corneal disease or trauma. Slit-lamp examination showed central epithelial defect with stromal infiltration and hypopyon. Microbiological examinations were performed from corneal scrapings 


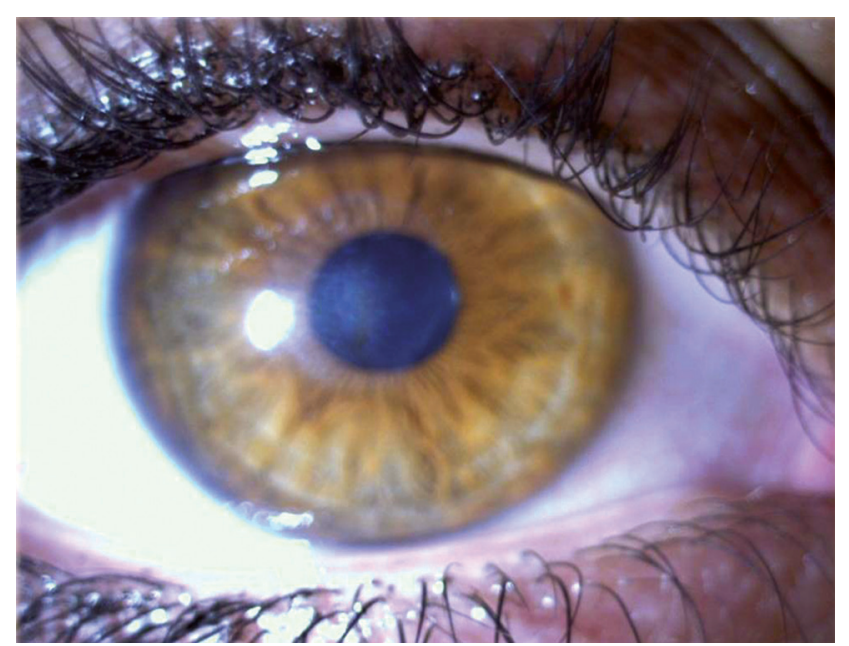

Fig. 1: Residual subepithelial corneal opacity in the right eye (Case 1)

and were positive for Pseudomonas aeruginosa. Empiric antibiotic treatment was started with ophthalmic solutions of Cefazolin and Tobramycin, with good clinical response. After healing epithelial defect and having the infectious focus under control, mild topical steroids (Fluorometholon acetate) were used to reduce corneal scarring.

Seven years later, she presented with a slight residual subepithelial corneal opacity (Fig. 1). Uncorrected distance visual acuity (UDVA) was 20/30 OD and 20/200 in the left eye (OS). Manifest refraction was a -2.5 cylinder leading to $20 / 30$ in OD and -5.00 sphere in OS, leading to $20 / 20$. Pentacam ${ }^{\circledR}$ showed a thinnest spot in the pachymetry map of $363 \mu \mathrm{m}$ OD and $513 \mu \mathrm{m}$ OS and reduced central medium keratometry of 37.0D OD compared to 43.6D OS (Fig. 2).

The second case is a 22-year-old male, cosmetic contact lens user, first presented with severe keratitis in OD. Significant worsening was reported 24 hours after topical empiric antibiotic therapy, with ciliary injection, stromal infiltration and hypopyon. Microbiologic work up revealed Pseudomonas aeruginosa. There was only modest clinical improvement despite intensive topical treatment with fortified antibiotics (Vancomycin and Gentamicin). Empiric treatment for Acanthamoeba was initiated with no resolution of keratitis, when he presented to Contarini Eye Clinic, Rio de Janeiro, Brazil (Fig. 3). After 4 negative corneal scrapings, empiric antifungal therapy was initiated with a good clinical response. After healing epithelial defect and reducing stromal infiltrate, topical steroids and immunosuppressive agents (Tacrolimus) were used to minimize stromal scarring. One year later, the eye was quiet and patient was referred to the Instituto de Olhos Renato Ambrósio, Rio de Janeiro, Brazil for considering therapeutic surgery. ${ }^{8}$ At ophthalmological evaluation he presented with moderate corneal opacity in OD (Fig. 4). UDVA was 20/150 in OD and 20/25 in OS and best spectacle corrected visual acuity was 20/40 OD and 20/20 OS. Total corneal thickness was $228 \mu \mathrm{m}$ in OD and $561 \mu \mathrm{m}$ in OS. Significant protrusion and irregular curvature in the right eye were observed by corneal tomography (Fig. 5). Due to the severe thinning, no therapeutic corneal ablation was considered. Before keratoplasty, patient was referred for contact lens fitting trial. Rigid gas permeable fitting enabled visual acuity of 20/25 in OD.

\section{DISCUSSION}

The breakdown of the unique corneal defenses through alterations in the natural biology of the epithelium, such as those reported during contact lens wear, predispose to infection. ${ }^{9}$ Contact lens-related microbial keratitis is the most visually devastating complication associated with contact

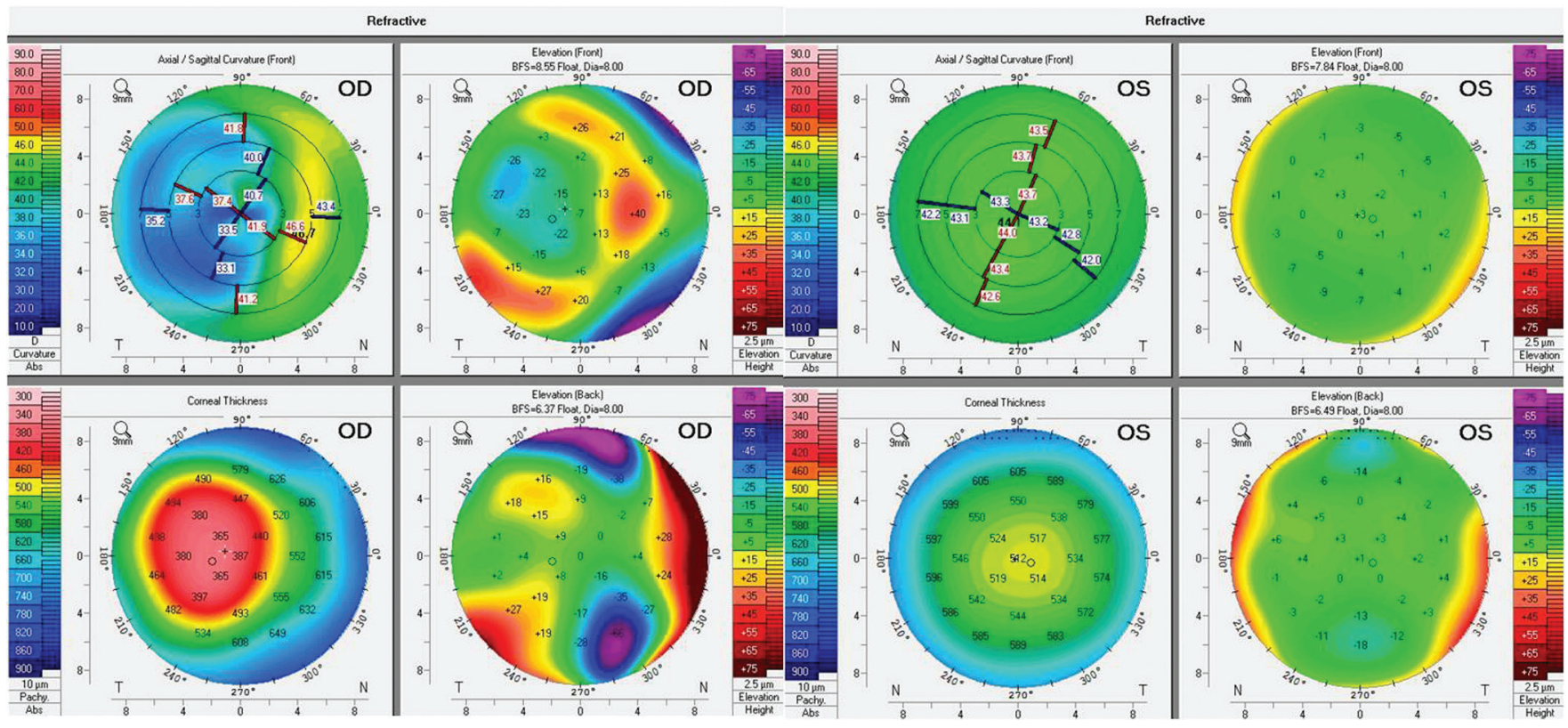

Fig. 2: Pentacam ${ }^{\circledR}$ four maps refractive (Case 1) 


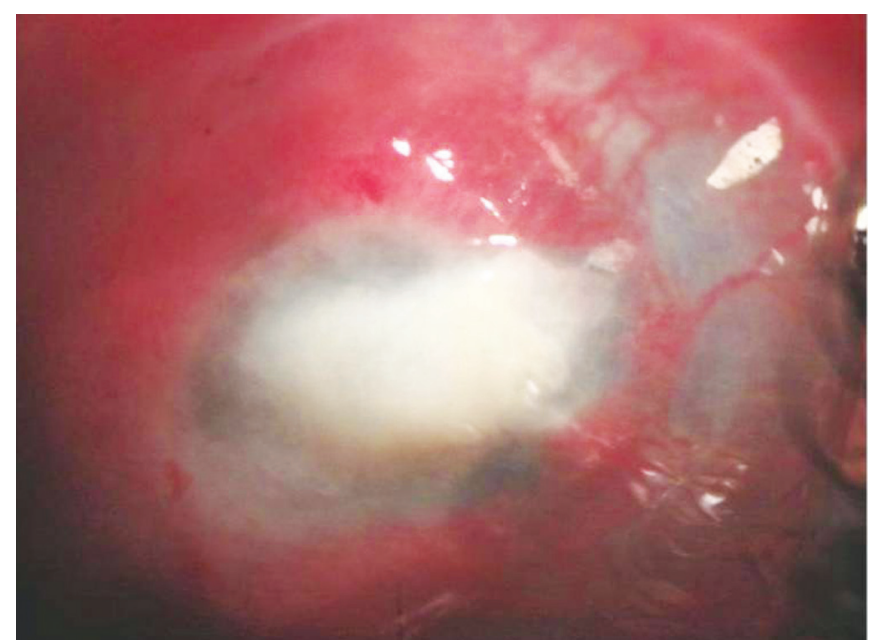

Fig. 3: Right eye biomicroscopy in the first presentation to Contarini Eye Clinic (Case 2)

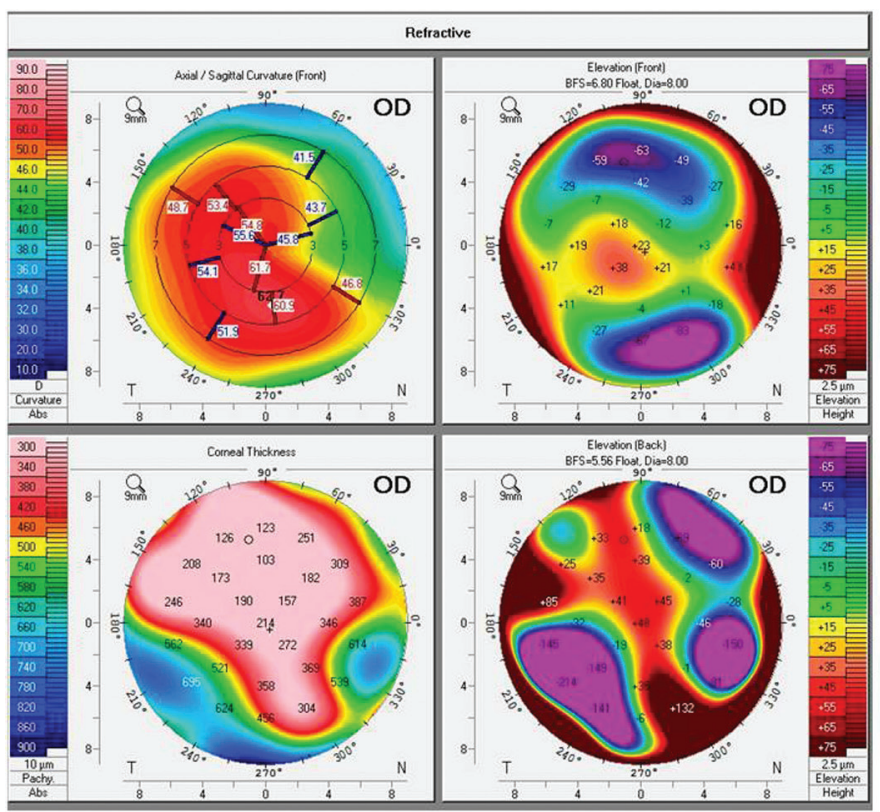

Fig. 5: Pentacam ${ }^{\circledR}$ four maps refractive (Case 2)

lens wear and for more than three decades, Pseudomonas aeruginosa has been consistently identified as the primary infectious pathogen. ${ }^{10-13}$ In the healing phase, corneal melt occurs leading to stromal loss and thinning, which may lead to secondary ectasia.

In these two cases, there was thinning due to the corneal melt related to the infection. Secondary ectasia progression occurred in the second case, while the first case had less thinning which did not compromise biomechanical integrity. The result of this process was moderate flattening with partial resolution of myopia, despite of moderate irregularity. Irregular astigmatism with higher order aberrations limits spectacle corrected visual acuity, which could be treated by contact lens or therapeutic corneal surgery. ${ }^{14}$

In the second case, corneal thinning was more pronounced leading to biomechanical failure and ectatic progression. Moderate scarring and corneal opacity was also present.

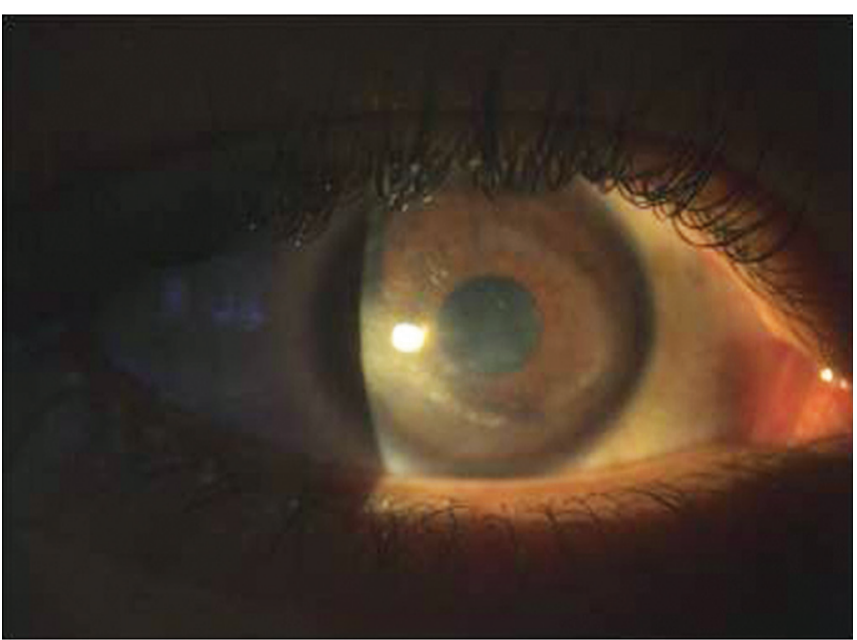

Fig. 4: Right eye biomicroscopy 1 year after treatment (Case 2)

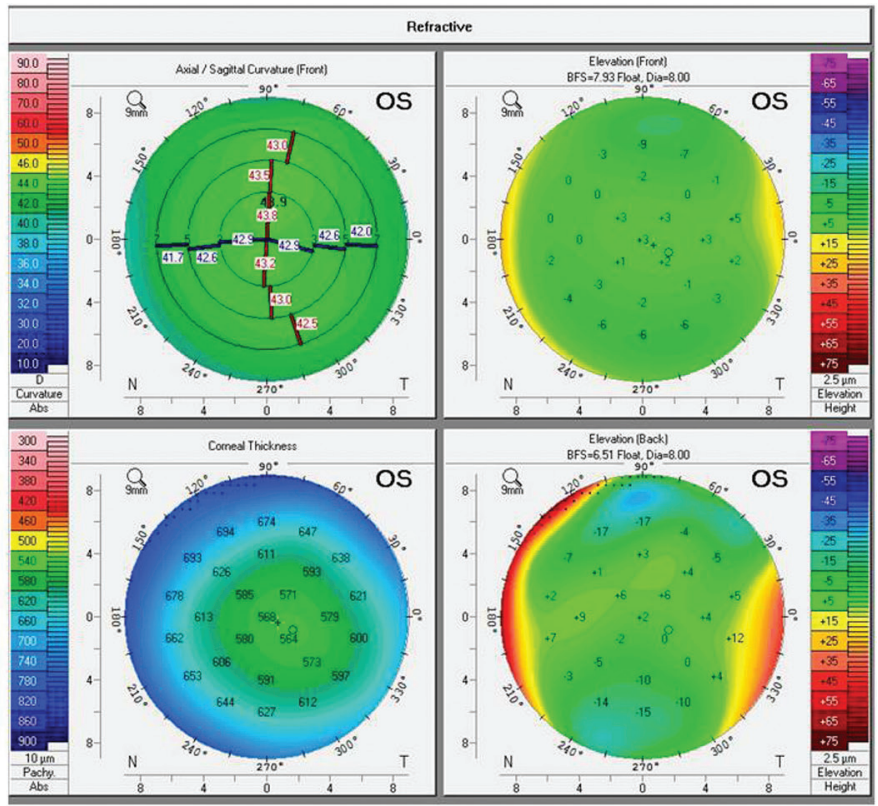

Nevertheless, we obtained good visual outcome with contact lens fitting.

The risk for infectious keratitis among contact lenses users should always be considered. The prevention of lensinduced inflammatory-mediated epithelial surface damage should be the main focus when fitting contact lenses. Patient education has a major role in this prevention process. Epithelial compromise becomes a zero sum game in which lens type, wearing modality and cleaning solution must be optimized.

\section{REFERENCES}

1. Krachmer JH, Feder RS, Belin MW. Keratoconus and related noninflammatory corneal thinning disorders. Surv Ophthalmol 1984 Jan Feb;28(4):293-322.

2. Seiler T, Quurke AW. Iatrogenic keratectasia after LASIK in a case of forme fruste keratoconus. J Cataract Refract Surg 1998 Jul; 24(7):1007-1009. 
3. Dupps WJ Jr, Wilson SE. Biomechanics and wound healing in the cornea. Exp Eye Res 2006 Oct;83(4):709-720.

4. Wojcik KA, Blasiak J, Szaflik J, Szaflik JP. Role of biochemical factors in the pathogenesis of keratoconus. Acta Biochim Pol 2014;61(1):55-62.

5. Health Quality Ontario. Intrastromal corneal ring implants for corneal thinning disorders: an evidence-based analysis. Ont Health Technol Assess Ser 2009;9(1):1-90.

6. Silverman RH, Urs R, Roychoudhury A, Archer TJ, Gobbe M, Reinstein DZ. Epithelial remodeling as basis for machine-based identification of keratoconus. Invest Ophthalmol Vis Sci 2014 Mar 13;55(3):1580-1587.

7. Hafezi F. Significant visual increase following infectious keratitis after collagen cross-linking. J Refract Surg 2012;28(8): 587-588.

8. Ambrósio Jr, Renato. Cirurgia refrativa terapêutica: por que diferenciar? Revista Brasileira de Oftalmologia 2013;72(2): 85-86.
9. Robertson DM. The effects of silicone hydrogel lens wear on the corneal epithelium and risk for microbial keratitis. Eye Contact Lens 2013 Jan;39(1):67-72.

10. Pachigolla G, Blomquist P, Cavanagh HD. Microbial keratitis pathogens and antibiotic susceptibilities: a 5-year review of cases at an urban county hospital in North Texas. Eye Contact Lens 2007;33(1):45-49.

11. Ormerod LD, Smith RE. Contact lens-associated microbial keratitis. Arch Ophthalmol 1986;104(1):79-83.

12. Mondino BJ, Weissman BA, Farb MD, Pettit TH. Corneal ulcers associated with daily-wear and extended-wear contact lenses. Am J Ophthalmol 1986;102(1):58-65.

13. Erie JC, Nevitt MP, Hodge DO, Ballard DJ. Incidence of ulcerative keratitis in a defined population from 1950 through 1988. Arch Ophthalmol 1993;111(12):1665-1671.

14. Ambrósio R Jr, Jardim D, Netto MV, Wilson SE. Management of unsuccessful LASIK surgery. Compr Ophthalmol Update. 2007 May-Jun;8(3):125-141; discussion 143-144. 